\title{
USE OF PROBIOTIC ACID BACTERIA FOR THE CONTROL OF MULTIDRUG RESISTANT BACTERIA ISOLATED FROM CLINICAL INFECTIONS
}

\author{
Gamal M. A. Lashin ${ }^{1}$, Eman Y. Tohamy ${ }^{2}$, Ahmed A. Askora ${ }^{2}$ and Fatma, \\ El-Zahraa Mahmoud ${ }^{2}$ \\ ${ }^{1}$ Department of Botany, Faculty of Science, Zagazig University, Zagazig, Egypt. \\ ${ }^{2}$ Department of Microbiology, Faculty of Science, Zagazig University, Zagazig, Egypt.
}

\begin{abstract}
This study was carried out to evaluate the microbial infections in natural way and reduce the antibiotic resistance. One hundred bacterial isolates were collected from clinical specimens of patients suffering from bacterial infection (55 females and 45 males). The bacterial isolates were obtained from 8 different specimens with the following percentage representations: urine (30.58 \%), blood (20\%), abscess (20\%), wound (9.41\%), throat and tube swab (5.88\%), ear discharges (5.88\%), vaginal swabs (5.88\%) and eye swab (2.35\%).The results showed that (29.41\%) Escherichia coli, (23.53\%) Klebsiella pneumoniae, (17.65\%) Staphylococcus aureus, (15.29\%) Pseudomonas aeruginosa, (8.24\%) Proteus vulgaris, (5.88\%) Acinetobacter baumannii. Among 17 antibiotics tested, meropenem, a carbapenem antibiotic, was the most effective drug against most of the gram-negative and gram-positive bacteria. Detection of biofilm by two different methods show that most of isolates were multidrug resistant. Three species of lactic acid bacteria namely L.acidophilus (DSM20079), L.plantarum (DSM20174) and L.salivarus (DSM20555) were used for reducing the microbial infections. Bacteriocins were isolated from MRS broth culture of these lactic acid bacteria through the precipitation method using $1 \mathrm{~N} \mathrm{HCL}$ and were tested against different pathogenic bacteria. Antibacterial activity of bacteriocins extracted from L. acidophilus (DSM20079) showed maximum activity against most isolated bacteria as compare to others. Also, L.salivarus (DSM20555) have the highest activity against Methicillin-resistant Staph aureus. The present study has showed the antibacterial role of bacteriocin isolated from lactic acid bacteria can be used for treatment variety of human diseases.
\end{abstract}

Keywords: Multidrug resistance, Role of Meropenem, Lactic acid bacteria $(\mathrm{LAB})$ and bacteriocins. 


\section{Introduction}

Multidrug resistant bacteria are defined as abroad category of bacteria resistant to common antibiotics (Abigail, 2010). Antimicrobial resistance (AMR) in bacteria is a great concern to the health and welfare of both human and animals (McDermott et al., 2016 and Zawack et al., 2016).

The increase and spread of multidrug resistant (MDR) bacteria have become a major concern worldwide. The hospital acquired infections caused by MDR bacteria have led not only to an increase in mortality, morbidity, and cost of treatment, but also continue to endanger the life of patients (Martin and Yost, 2011 and Delle Rose et al., 2015). MDR bacteria can cause a wide range of infections, including bacteremia, pneumonia, urinary tract infection, peritonitis etc., which can lead to substantial morbidity and mortality, particularly in the ICU settings (Chen et al., 2001).

Microbes become antibiotic resistant due to partial exposure to one or more antibiotics. Gene mutations as well as vertical and horizontal gene transfer among bacteria are also important factors for development of resistance (Levy, 1997 and Salyers, 1995). Also, it has been reported that AMR kills around 50.000 people a year in US and Europe, and is estimated to kill more than 700.000 people globally (O'Neill, 2016). If no action was made to reduce AMR, probably, 10 million people would die every year from drugresistant infections by the year of 2050 (O'Neill, 2016).

The increase of multidrug-resistant bacteria and the restriction on the use antibiotics due to its side effects have drawn attention to search for possible alternatives. Probiotic LAB can act synergistically or have an additive effect in the antimicrobial activity when combined with other antimicrobials (Viedma et al., 2010 and Gómez et al., 2012). Lactic acid bacteria (LAB) constitute part of the autochthonous microbiota of many types of food. They are defined as non- spore forming, gram- positive rods cocci as well as catalase- negative bacteria which share many biochemical, physiological, and genetic properties (Abriouel et al., 2012). Interestingly, LAB may simultaneously secrete organic acids, bacteriocins and biosurfactants (Kanmani et al., 2013). Bacteriocins are small antimicrobial peptides produced by numerous lactic acid bacteria. Much interest has been focused on bacteriocins because they exhibit inhibitory activity against pathogens. So, $\mathrm{LAB}$ is helpful in treatment without raising the antibiotic resistance level (Stiles, 1996).

Bacteriocins are antimicrobial peptides produced by many lactic acid bacteria, which are directed mainly to inhibit the growth of related species or species with the same nutritive requirements (DeVuyst, 1995, Jack et al., 1995 and Todorov and Dicks, 2005). Bacteriocins differ from most therapeutic antibiotics in being proteinaceous agents that are rapidly digested by proteases 
in the human digestive tract. They are ribosomally synthesized peptides, and this fact creates the possibility of improving their characteristics to enhance their activity and spectra of action (Saavedra $\boldsymbol{e t}$ al., 2004). Thus, the aim of study was focused on extraction of bacteriocins from LAB and determination of its antibacterial effect against different antibiotic resistant pathogenic bacterial strains.

\section{Materials and Methods}

\section{Collection and isolation of pathogenic bacteria}

One hundred clinical samples were collected from different patients suffering from bacterial infection. All clinical samples were collected by standard microbiological technique (Cheensbourgh, 2006). The sources of specimens were pus/swab from wound, urine, ear discharge, blood, throat/tube swab, abscess, vaginal swab and eye swab. Depending on the source of samples, each specimen were platted on to Nutrient agar, MacConkey agar, Blood agar and CLED agar media (Oxoid, UK) and then incubated aerobically at $37 \mathrm{C}$ for 24-48h.

\section{Identification of pathogenic bacteria isolated from different specimens}

All the bacteria were identified by using cell morphology, Gram staining and conventional biochemical methods according to standard microbiological techniques (Forbes et al., 1998 and Cheesbourgh, 2006). Also, to confirm identification of selected bacteria, specific gene using specific primers was performed using PCR technique by using agarose gel used for separation of amplified genes in the selected isolates.

\section{Antimicrobial susceptibility testing}

Antimicrobial susceptibility was done on Muller-Hinton agar (Oxoid, England) using standard disk diffusion technique according to Kirby-Bauer method (Muller-Hinton 1941), (Bauer et al., 1966) and (Raja and Singh 2007).The antimicrobial agents tested were: Amoxicillin/clavulanic acid $(30 \mu \mathrm{g})$, piperacillin $(100 \mu \mathrm{g})$, cefadroxil $(30 \mu \mathrm{g})$, oxacillin $(1 \mu \mathrm{g})$, cefotaxime $(30 \mu \mathrm{g}), \quad$ ceftazidime $(30 \mu \mathrm{g}), \quad$ amikacin $(30 \mu \mathrm{g}), \quad$ gentamycin $(10 \mu \mathrm{g})$ trimethoprim/sulphamethoxazole $(25 \mu \mathrm{g}), \quad$ doxycycline $(30 \mu \mathrm{g})$, vancomycin $(30 \mu \mathrm{g})$, nitrofurantion $(300 \mu \mathrm{g})$, linezolid $(30 \mu \mathrm{g})$ and ciprofloxacin $(5 \mu \mathrm{g})$ (Oxoid, England). The antibiotic susceptibility profiles were interpreted based on Clinical and Laboratory Standards Institute (CLSI, 2006) guidelines. Moreover, MDR profile was determined against different classes of antimicrobials: Cephalosporin class (cefadroxil, cefotaxime, ceftazidime), Penicillin class (amoxicillin/clavulanic acid, piperacillin, oxacillin), Aminoglycosides class (gentamycin, amikacin), Quinolone class (ciprofloxacin), Glycopeptides class (vancomycin), Tetracycline class (doxycycline), Macrolides class (erythromycin, azithromycin) and 
Carbapenem (meropenem). The zones of inhibition of bacterial isolates for these antibiotics were measured in $\mathrm{mm}$ by applying ordinary ruler.

\section{Detection of biofilm of multi-drug resistant bacteria}

After isolation and identification of bacterial isolates, detection of biofilm formation was done by two different methods (Tube method and Congo red agar method) to detect bacterial resistance of isolates (Hassan, et al., 2011).

\section{Tube method}

Trypticase soy broth with $1 \%$ glucose (TSB) $(10 \mathrm{~mL})$ was inoculated with a loopful of microorganism from overnight culture plates and incubated for 24 $\mathrm{h}$ at $37^{\circ} \mathrm{C}$. After incubation, tubes were decanted and washed with phosphate buffer saline ( $\mathrm{pH} 7.3)$ and dried. Dried tubes were then stained with crystal violet $(0.1 \%)$. Excess stain was removed, and tubes were washed with deionized water. Tubes were then dried in inverted position and observed for biofilm formation.

\section{Congo red agar method (CRA)}

This method requires the use of a specially prepared solid medium brain heart infusion broth (BHI) supplemented with 5\% sucrose and Congo red. The medium was composed of BHI (Oxoid, UK) $37 \mathrm{~g} / \mathrm{L}$, sucrose $50 \mathrm{~g} / \mathrm{L}$, agar No.1 (Oxoid, UK) $10 \mathrm{~g} / \mathrm{L}$ and Congo Red stain 0.8 g/L. Congo Red was prepared as a concentrated aqueous solution and autoclaved at $121^{\circ} \mathrm{C}$ for 15 minutes, separately from other medium constituents and was then added when the agar had cooled to $55^{\circ} \mathrm{C}$. Plates were inoculated with test organisms and incubated aerobically for 24 to $48 \mathrm{~h}$ at $37^{\circ} \mathrm{C}$. Positive result was indicated by black colonies with a dry crystalline consistency.

\section{Activation of lactobacillus strains}

Lyophilized strains of Lactobacillus acidophilus (DSM20079), Lactobacillus plantarum (DSM20174) and Lactobacillus salivarius (DSM20555) were obtained from Cairo, MIRCEN (Microbiological Resource Center), Faculty of Agriculture, Ain Shams University, Cairo, Egypt. All strains were activated on MRS broth (De Man, Rogosa and Sharp which obtained from Biolife, Italy) at $37 \mathrm{C}$ for $24 \mathrm{~h}$. Then three culture transfers performed to activate each culture.

\section{Extraction of bacteriocin}

Ten $\mathrm{ml}$ of activated culture of each strain were separately inoculated into one liter of MRS broth under aseptic conditions and incubated at $37^{\circ} \mathrm{C} / 16 \mathrm{~h}$. as described by (Hurst, 1966 and Abd El.Fattah, 1999). All bacteriocin producing cultures were adjusted to $\mathrm{pH} 2.0$ by adding $\mathrm{HCl} 1 \mathrm{~N}$ then cultures were heated in water bath at $100^{\circ} \mathrm{C}$ for $5 \mathrm{~min}$. The cells were harvested by centrifugation at $10.000 \mathrm{rpm}$ for $20 \mathrm{~min}$. at $4^{\circ} \mathrm{C}$ and recentrifugated under the same conditions. The supernatants containing bacteriocin extracts were 
collected for every strain (Savadogo et al., 2004). Then, bacteriocin extracts were sterilized by using Seitz filter with single sheet to eliminate the possible presence of viable bacterial cells (Simova et al., 2009).

\section{Determination of antibacterial activity}

Bacteriocin activity was assayed by disk diffusion assay (Tagg et al., 1976).

This method is described as follows:

Serial Dilutions were prepared from isolated pathogenic bacteria till obtain concentration of $1 \times 10^{6} \mathrm{CFU} / \mathrm{ml}$ (Abd El-Fattah, 1999). One $\mathrm{ml}$ quantities from approximately $1 \times 10^{6} \mathrm{CFU} / \mathrm{ml}$ from each pathogenic were inoculated on Muller-Hinton agar. Sterile filter papers were saturated with $100 \mu \mathrm{L}$ of sterilized bacteriocin then plates were allowed prior to incubation at $37^{\circ} \mathrm{C} / 24$ $\mathrm{h}$. and then examined for clear circular inhibition zone around the disk. The titer of inhibition was defined as the reciprocal of the highest dilution showing definite inhibition zone. Bacteriocins activity was recorded as positive if width of clear inhibition zone around the colonies of the producer was $2 \mathrm{~mm}$ or larger (Chumcholova et al., 2004 and Anastasiadou et al., 2008).

\section{Results}

Among the 100 samples were collected from different patients suffering from bacterial infections, 85 samples were positive (85\% of total sample) and 15 samples were negative (15\% of total samples). The total females samples were 55 and males samples were 45 (Table 1).

The bacterial isolates were obtained from 8 different specimens with the following percentage representations: Urine (30.58 \%), blood (20\%), abscess (20\%), wound $(9.41 \%)$, throat and tube swab (5.88\%), ear discharges $(5.88 \%)$, vaginal swabs $(5.88 \%)$ and eye swab (2.35\%) as shown in Table 2. The commonest organisms isolated from all samples were E.coli 25 (29.41\%), Klebsiella pneumoniae 20 (23.52\%), Staph. aureus 15 (17.64\%), Pseudomonas aeruginosa 13 (15.29\%), Proteus vulgaris $7(8.23 \%)$ and Acinetobacter baumannii 5 (5.88\%) (Table 2). E.coli ranked first overall among patients 25 (29.41\% of total sample) in which was isolated from urine $15(57.69 \%)$, blood $1(5.88 \%)$, abscess $3(17.64 \%)$, wound $2(25 \%)$, throat and tube $2(40 \%)$ and vaginal $2(40 \%)$. Also, Klebsiella pneumoniae ranked second overall among patients 20 (23.52\% of total samples) in which was isolated from urine 5 (19.2\%), blood 7 (41.17\%), abscess 4 (23.5\%), wound 2 (25\%) and vaginal 2 (40\%) (Table 2). E.coli was the most organisms isolated from urine samples (57.69\%), while Staph aureus the most organisms isolated from blood stream (47.05\%) and eye swabs (50\%). Also, Pseudomonas aeruginosa the most organisms isolated from abscess swabs (35.29\%) and ear swab (40\%) as recorded in Table 2. 
Methicillin resistant Staph.aureus (MRSA) comprised $40 \%$ of all Staph.aureus isolates $(6 / 15)$ in which 4 isolates from blood stream, one isolated from abscess and one isolated from ear discharge. Also, among Gram negative isolates there are ESBL isolates in which $3(15 \%)$ cases from all Klebsiella pneumoniae isolates (3/20), two cases (28.57\%) from all Proteus vulgaris (3/7) and two cases (15.38\%) from all pseudomonas aeruginosa $(2 / 13)$.

All isolates were identified by agarose gel PCR technique depending on specific gene of each organism whereas, (16SrDNA) specific gene of P.aeruginosa, (atpD) specific gene of P. vulgaris, (recA) specific gene of (A.baumannii), (16S-23S ITS) specific gene of K.pneumoniae, (clfA) specific gene of Staph.aureus and (phoA) specific gene of E.coli (Fig.1).

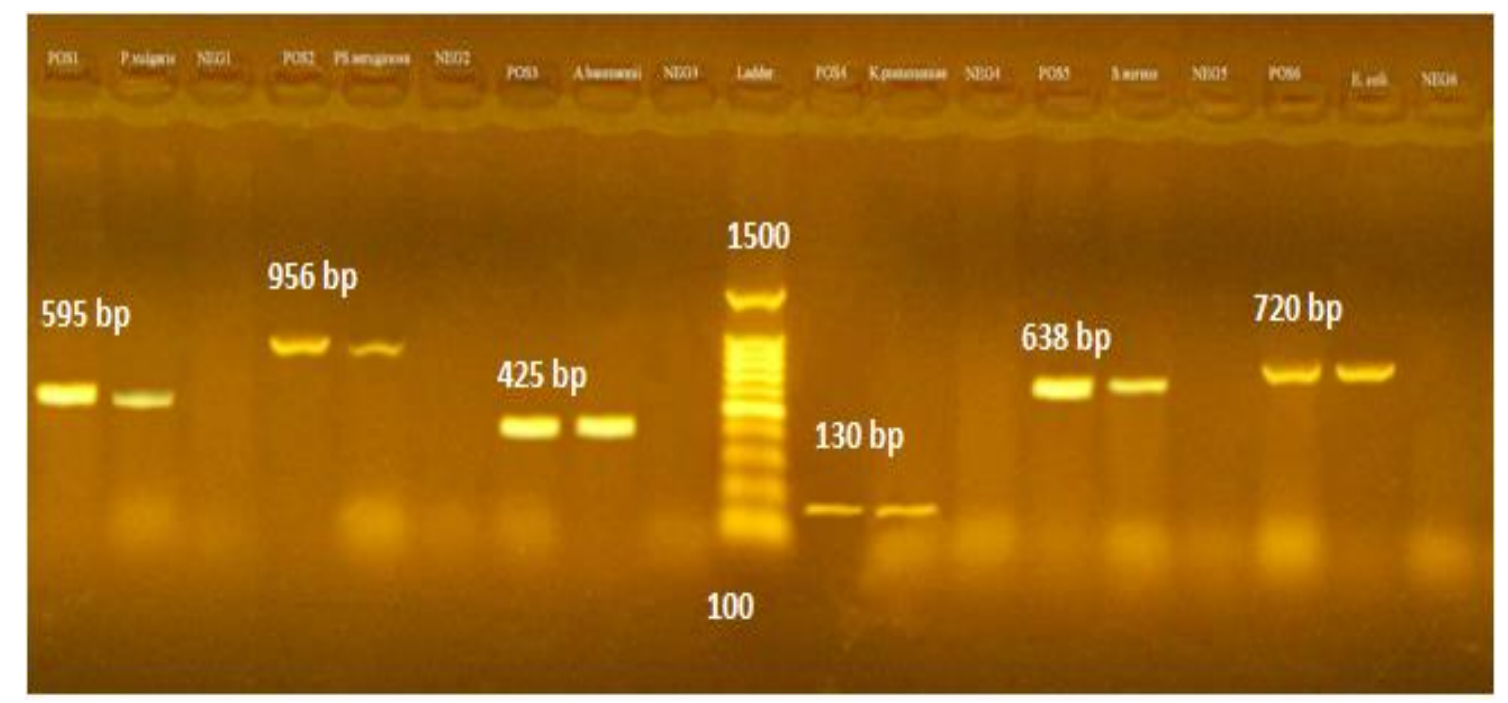

Figure (1): A photograph of agarose gel showing PCR products of partially amplified of $\mathrm{S} 1$ ( $P$. vulgaris at atpD gene at $595 \mathrm{bp}), \mathrm{S} 2(P$. aeruginosae at 16SrDNA gene at 956bp), S3 (A. baumannii at recA gene at $425 \mathrm{bp}), \mathrm{S} 4$ ( $K$. pneumoniae at 16S-23S ITS gene at $130 \mathrm{bp}$ ), S5 (Staph. aureus at clfA gene at $638 \mathrm{bp}), \mathrm{S} 6$ (E.coli at phoA gene at $720 \mathrm{bp})$.

N.B: Pos.: Positive control strains from reference lab. of veterinary quality control on poultry production, Dokki, Giza.

Neg.: Negative control strains from reference lab. of veterinary quality control on poultry production Dokki, Giza. 
Table (1): Age and sex distribution of common bacterial isolates from various sites of infections among patients

\begin{tabular}{|c|c|c|c|c|c|}
\hline \multirow{3}{*}{ Type of isolates } & \multicolumn{4}{|c|}{ Sex } & \multirow{3}{*}{$\begin{array}{r}\text { Total } \\
n=100\end{array}$} \\
\hline & \multicolumn{2}{|c|}{$\begin{array}{c}\begin{array}{c}\text { Female } \\
n=55\end{array} \\
\end{array}$} & \multicolumn{2}{|c|}{$\begin{array}{l}\text { Male } \\
n=45\end{array}$} & \\
\hline & No. & $\%$ & No. & $\%$ & \\
\hline E. coli & 16 & 29.09 & 9 & 20 & 25 \\
\hline K. pneumonia & 11 & 20 & 9 & 20 & 20 \\
\hline Staph.aureus & 8 & 14.54 & 7 & 15.55 & 15 \\
\hline P.aeruginosa & 7 & 12.72 & 6 & 13.3 & 13 \\
\hline Proteus Vulgaris & 4 & 7.27 & 3 & 6.66 & 7 \\
\hline A.baumannii & 2 & 3.63 & 3 & 6.66 & 5 \\
\hline$N G$ & 7 & 12.7 & 8 & 17.77 & 15 \\
\hline
\end{tabular}

$\mathrm{NG}=$ no growth of organisms; $\mathrm{n}=$ total number of patients in each sex.

Table (2): Occurrence rates of bacteria in clinical samples collected from different site of infections occurred among patients

\begin{tabular}{|c|c|c|c|c|c|c|c|c|c|c|c|c|c|c|c|c|c|c|}
\hline \multirow{3}{*}{ Organism } & \multicolumn{16}{|c|}{ Type of clinical specimens } & & \\
\hline & \multicolumn{2}{|c|}{$\begin{array}{c}\text { Urine } \\
\text { n=26 }\end{array}$} & \multicolumn{2}{|c|}{$\begin{array}{c}\text { Blood } \\
\mathbf{n}=24\end{array}$} & \multicolumn{2}{|c|}{$\begin{array}{c}\text { Abscess } \\
\mathrm{n}=22\end{array}$} & \multicolumn{2}{|c|}{$\begin{array}{c}\text { Wound } \\
\mathbf{n}=8\end{array}$} & \multicolumn{2}{|c|}{$\begin{array}{c}\text { Throat } \\
\text { n=6 }\end{array}$} & \multicolumn{2}{|c|}{$\begin{array}{l}\text { Ear } \\
n=5\end{array}$} & \multicolumn{2}{|c|}{$\begin{array}{c}\text { Vaginal } \\
\mathbf{n}=5\end{array}$} & \multicolumn{2}{|c|}{$\begin{array}{l}\text { eye } \\
n=4\end{array}$} & \multicolumn{2}{|c|}{$\begin{array}{c}\text { Total } \\
n=100\end{array}$} \\
\hline & No & $\%$ & No & $\%$ & No & $\%$ & No & $\%$ & No & $\%$ & No & $\%$ & No & $\%$ & No & $\%$ & No & $\%$ \\
\hline E. coli & 15 & 57.69 & 1 & 5.88 & 3 & 17.64 & 2 & 25 & 2 & 40 & 0 & 0 & 2 & 40 & 0 & 0 & 25 & 29.41 \\
\hline $\begin{array}{c}\text { Klebsiella } \\
\text { Pneumonia }\end{array}$ & 5 & 19.2 & 7 & 41.17 & 4 & 23.5 & 2 & 25 & 0 & 0 & 0 & 0 & 2 & 40 & 0 & 0 & 20 & 23.52 \\
\hline Staph.aureus & 0 & 0 & 8 & 47.05 & 2 & 11.76 & 0 & 0 & 2 & 40 & 1 & 20 & 0 & 0 & 2 & 50 & 15 & 17.64 \\
\hline P.aeruginosa & 2 & 7.69 & 0 & 0 & 6 & 35.29 & 2 & 25 & 1 & 20 & 2 & 40 & 0 & 0 & 0 & 0 & 13 & 15.29 \\
\hline $\begin{array}{c}\text { Proteus } \\
\text { vulgaris } \\
\end{array}$ & 2 & 7.69 & 0 & 0 & 1 & 5.88 & 1 & 12.5 & 0 & 0 & 2 & 40 & 1 & 20 & 0 & 0 & 7 & 8.23 \\
\hline A.baumannii & 2 & 7.69 & 1 & 5.88 & 1 & 5.88 & 1 & 12.5 & 0 & 0 & 0 & 0 & 0 & 0 & 0 & 0 & 5 & 5.88 \\
\hline $\begin{array}{c}\text { Total } \\
\text { isolation rate }\end{array}$ & 26 & 30.58 & 17 & 20 & 17 & 20 & 8 & 9.41 & 5 & 5.88 & 5 & 5.88 & 5 & 5.88 & 2 & 2.35 & 85 & 100 \\
\hline
\end{tabular}

$\mathrm{n}=$ total number of clinical specimen.

\section{Antimicrobial susceptibility profiles of bacterial isolates}

Among 17 antibiotics, meropenem was the most effective drug against most of the gram-negative and gram-positive bacteria 25 E.coli (92.3\%), 20 K.pneumoniae (85\%), 13P.aeruginosa (76.9\%), 7P.vulgaris (85.7\%), 5 A.baumannii (80\%) and 15 Staph.aureus $(73.33 \%)$ as written in Table 3. E.coli was more resistant to cefadroxil (96\%), doxycycline (90\%), piperacillin $(88 \%)$, erythromycin (88\%) and trimethoprim/sulphamethoxazole (80\%). All K.pneumoniae was resistant to cefadroxil (100\%) and more resistant to doxycycline $(95 \%)$, piperacillin $(90 \%)$, erythromycin $(85 \%)$, cefotaxime (75\%) and ceftazidime (75\%). In other hand, all P.aeruginosa was resistant to 
Cefadroxil (100\%) and more resistant to Doxycycline, Cefotaxime, erythromycin and Piperacillin $(92.3 \%, 84.61 \%, 69.23 \%$, and $69.23 \%$ respectively). P.vulgaris was more resistant to cefadroxil, doxycycline, erythromycin, piperacillin and trimethoprim/sulphamethoxazole $(85.7 \%$, $85.7 \%, 85.7 \%, 57.14 \%$ and $42.85 \%$ respectively). Also, A.baumannii similar other gram negative bacteria in which were resistant to cefadroxil, piperacillin, erythromycin, ciprofloxacin and trimethoprim/sulphamethoxazole (Table 4).

Vancomycin and linezolid have effect on Staph.aureus (80\% and 60\%) but cefadroxil, cefotaxime and ceftazidime were more resistant $(93.3 \%, 66.6 \%$ and $66.6 \%$ ). MRSA were resistant to all penicillin, cephalosporin and carbapenem.

Table (3): Antibiotics susceptibility patterns against 85 different bacterial isolates collected from one hundred different patients suffering from bacterial infection.

\begin{tabular}{|c|c|c|c|c|c|c|c|c|c|c|c|c|}
\hline \multirow[t]{2}{*}{ Antibiotics } & \multicolumn{2}{|c|}{$\begin{array}{l}\text { E.coli } \\
\mathrm{n}=25\end{array}$} & \multicolumn{2}{|c|}{$\begin{array}{c}\text { Klebsiella } \\
\text { pneumaniae } \\
\mathbf{n}=\mathbf{2 0}\end{array}$} & \multicolumn{2}{|c|}{$\begin{array}{c}\text { Staph. } \\
\text { aureus } \\
\mathrm{n}=15\end{array}$} & \multicolumn{2}{|c|}{$\begin{array}{c}\text { Pseudomonas } \\
\text { aeruginosa } \\
\mathrm{n}=13\end{array}$} & \multicolumn{2}{|c|}{$\begin{array}{c}\text { Proteus } \\
\text { vulgaris } \\
\mathrm{n}=7\end{array}$} & \multicolumn{2}{|c|}{$\begin{array}{c}\text { Acinetobacter } \\
\text { baumanii } \\
n=5\end{array}$} \\
\hline & No. & $\%$ & No. & $\%$ & No. & $\%$ & No. & $\%$ & No. & $\%$ & No. & $\%$ \\
\hline $\begin{array}{c}\text { Amoxicillin/Clavulanic } \\
\text { acid (AMC) }\end{array}$ & 9 & 36 & 5 & 25 & 7 & 46.66 & 2 & 15.38 & 3 & 42.85 & 0 & 0 \\
\hline Piperacillin (PRL) & 2 & 8 & 0 & 0 & 2 & 13.3 & 3 & 23.07 & 2 & 28.57 & 0 & 0 \\
\hline Cefadroxil (CFR) & 0 & 0 & 0 & 0 & 0 & 0 & 0 & 0 & 0 & 0 & 0 & 0 \\
\hline Oxacillin (OX) & -- & -- & -- & -- & 8 & 53.3 & -- & -- & -- & -- & -- & -- \\
\hline Cefotaxime (CTX) & 3 & 12 & 2 & 10 & 3 & 20 & 0 & 0 & 3 & 42.85 & 1 & 20 \\
\hline Ceftazidime (CAZ) & 7 & 28 & 1 & 5 & 3 & 20 & 3 & 23.07 & 3 & 42.85 & 1 & 20 \\
\hline Amikacin (AK) & 15 & 60 & 10 & 50 & 6 & 40 & 9 & 69.23 & 5 & 71.4 & 3 & 60 \\
\hline Gentamycin $(\mathrm{CN})$ & 16 & 64 & 8 & 40 & 10 & 66.66 & 8 & 61.53 & 4 & 57.14 & 2 & 40 \\
\hline Meropenem (MEM) & 23 & 92 & 17 & 85 & 11 & 73.33 & 10 & 76.9 & 6 & 85.7 & 4 & 80 \\
\hline Azithromycin (AZM) & 0 & 0 & 4 & 20 & 9 & 60 & 5 & 38.46 & 1 & 14.28 & 1 & 20 \\
\hline Erythromycin (E) & 2 & 8 & 2 & 10 & 8 & 53.3 & 3 & 23.07 & 1 & 14.28 & 0 & 0 \\
\hline $\begin{array}{c}\text { Trimethoprim/ } \\
\text { Sulphamethoxazole } \\
\text { (SKT) }\end{array}$ & 4 & 16 & 3 & 15 & 6 & 40 & 1 & 7.69 & 4 & 57.14 & 2 & 40 \\
\hline Doxycycline (DO) & 2 & 8 & 0 & 0 & 10 & 66.66 & 0 & 0 & 1 & 14.28 & 0 & 0 \\
\hline Vancomycin (VA) & -- & -- & -- & -- & 12 & 80 & -- & -- & -- & -- & -- & -- \\
\hline Nitrofurantion $(\mathbf{F})$ & 13 & 52 & 2 & 10 & 6 & 40 & 2 & 15.38 & 2 & 28.57 & 1 & 20 \\
\hline Linezolid (LZD) & 11 & 44 & 2 & 10 & 9 & 60 & 7 & 53.84 & 3 & 42.85 & 2 & 40 \\
\hline Ciprofloxacin (CIP) & 5 & 20 & 3 & 15 & 6 & 40 & 5 & 38.46 & 2 & 28.57 & 2 & 40 \\
\hline
\end{tabular}

$\mathrm{n}=$ number of isolates, $\%=$ percentage of antibiotics susceptibility 
Table (4): Antibiotics resistance patterns against 85 different bacterial isolates collected from one hundred different patients suffering from bacterial infection.

\begin{tabular}{|c|c|c|c|c|c|c|c|c|c|c|c|c|}
\hline \multirow[t]{2}{*}{ Antibiotics } & \multicolumn{2}{|c|}{$\begin{array}{l}\text { E.coli } \\
\mathrm{n}=25\end{array}$} & \multicolumn{2}{|c|}{$\begin{array}{c}\text { Klebsiella } \\
\text { pneumaniae } \\
\mathbf{n = 2 0}\end{array}$} & \multicolumn{2}{|c|}{$\begin{array}{c}\text { Staph. } \\
\text { aureus } \\
\mathrm{n}=15\end{array}$} & \multicolumn{2}{|c|}{$\begin{array}{c}\text { Pseudomonas } \\
\text { aeruginosa } \\
\mathrm{n}=13\end{array}$} & \multicolumn{2}{|c|}{$\begin{array}{c}\text { Proteus } \\
\text { vulgaris } \\
\mathbf{n}=7\end{array}$} & \multicolumn{2}{|c|}{$\begin{array}{c}\text { Acinetobacter } \\
\text { baumanii } \\
\mathbf{n}=5\end{array}$} \\
\hline & No. & $\%$ & No. & $\%$ & No. & $\%$ & No. & $\%$ & No. & $\%$ & No. & $\%$ \\
\hline $\begin{array}{c}\text { Amoxicillin/ } \\
\text { Clavulanic } \\
\text { acid (AMC) }\end{array}$ & 11 & 44 & 12 & 60 & 6 & 40 & 10 & 76.9 & 2 & 28.57 & 3 & 60 \\
\hline Piperacillin (PRL) & 22 & 88 & 18 & 90 & 12 & 80 & 9 & 69.23 & 4 & 57.14 & 4 & 80 \\
\hline Cefadroxil (CFR) & 24 & 96 & 20 & 100 & 14 & 93.33 & 13 & 100 & 6 & 85.7 & 5 & 100 \\
\hline Oxacillin $(\mathbf{O X})$ & -- & -- & -- & -- & 5 & 33.3 & -- & -- & -- & -- & -- & -- \\
\hline Cefotaxime(CTX) & 21 & 84 & 15 & 75 & 10 & 66.66 & 11 & 84.61 & 4 & 57.14 & 2 & 40 \\
\hline Ceftazidime (CAZ) & 15 & 60 & 15 & 75 & 10 & 66.66 & 8 & 61.53 & 3 & 42.85 & 3 & 60 \\
\hline Amikacin (AK) & 4 & 16 & 5 & 25 & 7 & 46.66 & 3 & 23.07 & 1 & 14.28 & 1 & 20 \\
\hline Gentamycin $(\mathrm{CN})$ & 7 & 28 & 8 & 40 & 3 & 20 & 3 & 23.07 & 1 & 14.28 & 1 & 20 \\
\hline Meropenem (MEM) & 0 & 0 & 0 & 0 & 2 & 13.3 & 2 & 15.38 & 0 & 0 & 0 & 0 \\
\hline $\begin{array}{c}\text { Azithromycin } \\
\text { (AZM) }\end{array}$ & 22 & 88 & 15 & 75 & 5 & 33.3 & 7 & 53.84 & 5 & 71.4 & 4 & 80 \\
\hline Erythromycin (E) & 22 & 88 & 17 & 85 & 6 & 40 & 9 & 69.23 & 6 & 85.7 & 4 & 80 \\
\hline $\begin{array}{c}\text { Trimethoprim/ } \\
\text { Sulphamethoxazole } \\
\text { (SKT) }\end{array}$ & 20 & 80 & 15 & 75 & 9 & 60 & 10 & 76.9 & 3 & 42.85 & 2 & 40 \\
\hline Doxycycline (DO) & 23 & 92 & 19 & 95 & 3 & 20 & 12 & 92.3 & 6 & 85.7 & 4 & 80 \\
\hline Vancomycin (VA) & -- & -- & -- & -- & 2 & 13.3 & -- & -- & -- & -- & -- & -- \\
\hline Nitrofurantion $(\mathbf{F})$ & 7 & 28 & 13 & 65 & 7 & 46.66 & 10 & 76.9 & 3 & 42.85 & 2 & 40 \\
\hline Linezolid (LZD) & 12 & 48 & 16 & 80 & 3 & 20 & 5 & 38.46 & 2 & 28.57 & 2 & 40 \\
\hline Ciprofloxacin (CIP) & 16 & 64 & 13 & 65 & 7 & 46.66 & 5 & 38.46 & 2 & 28.57 & 33 & 60 \\
\hline
\end{tabular}

$\mathrm{n}=$ number of isolates, $\%=$ percentage of antibiotics resista

\subsection{Detection of biofilm}

Tube method and Congo red agar were to detect biofilm in pathogenic bacteria and show that most isolates were multi-drug resistant. From two methods, it was obtained that most Gram negative bacteria have strong biofilm but Staph. aureus have weak biofilm except cases of MRSA have strong biofilm. 
Table (5): Correlation of biofilm production of different isolates with different clinical specimens.

\begin{tabular}{|c|c|c|}
\hline No. & Organism & Biofilm production \\
\hline 1 & A. baumannii & Strong \\
\hline 2 & K. pneumonia & Strong \\
\hline 3 & P. aeruginosa & Strong \\
\hline 4 & Staph.aureus & Weak \\
\hline 5 & $*$ MRSA & Strong \\
\hline 6 & $* *$ ESBLE & Strong \\
\hline 7 & E.coli & Moderate \\
\hline 7 & P.vulgaris & Strong \\
\hline
\end{tabular}

*MRSA=Methicillin resistant Staph.aureus $* *$ ESBL $=$ Extended Spectrum B-lactam

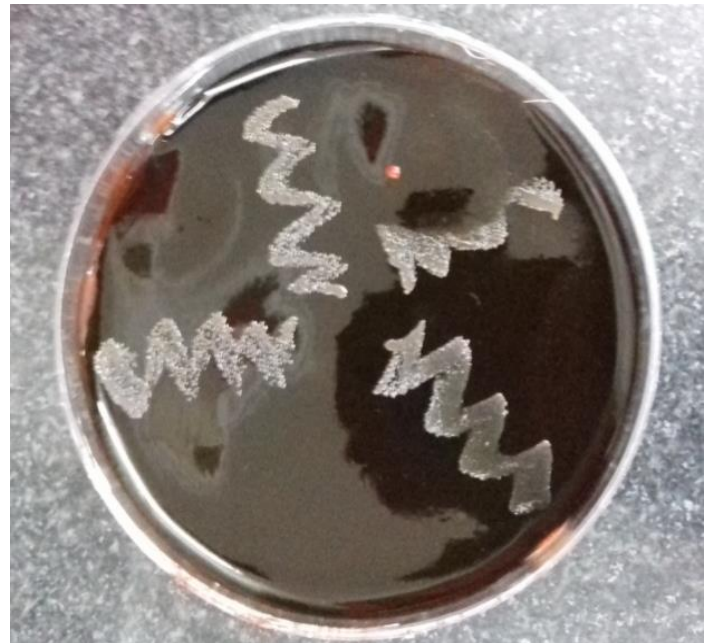

Figure (3): Positive biofilm by CRA method (Black color).

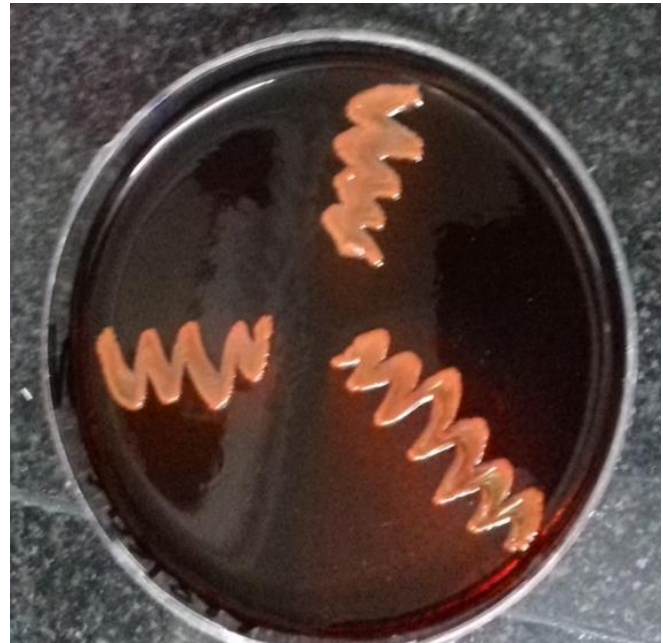

Figure (4): Negative biofilm by CRA method (Pink color).

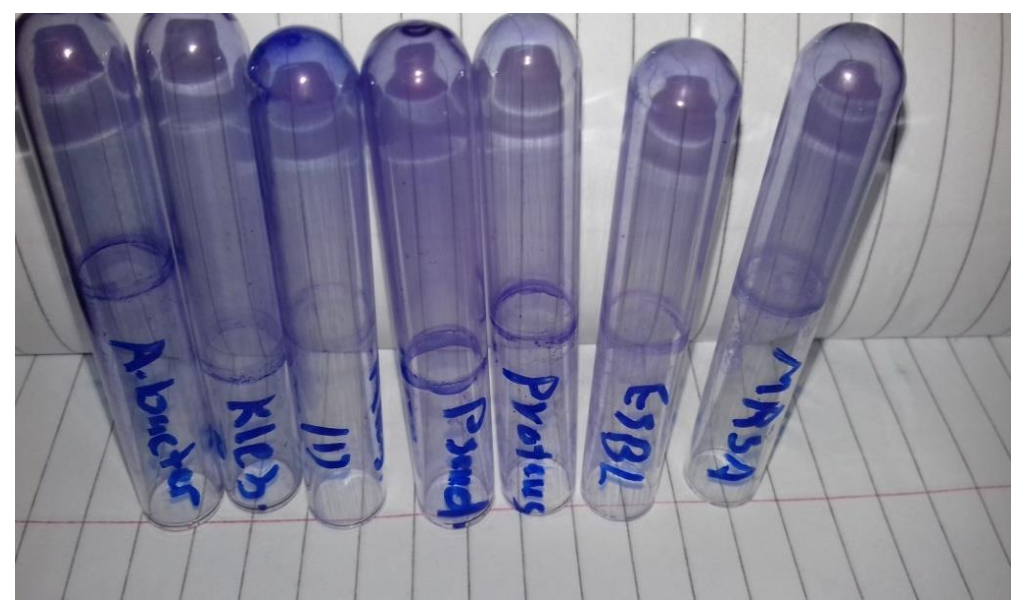

Figure (5): Biofilm of different isolates by the tube method (blue color) 


\section{Effect of bacteriocin extracted from Lactobacillus species on isolated pathogenic bacteria}

In this study, the production of bacteriocin from Lactobacillus acidophilus (DSM20079), Lactobacillus plantarum (DSM20174) and Lactobacillus salivarius (DSM20555) have effect on the growth of Gram- negative (E.coli, K. pneumaniae, P.aeruginosa, P.vulgaris and A.baumannii) and Grampositive bacteria Staph.aureus). The largest inhibition zone were obtained by bacteriocin extracted from Lactobacillus acidophilus (DSM20079) and the lowest inhibition zone of most Gram-negative pathogenic bacteria were obtained by Lactobacillus salivarius (DSM20555).

Results show that the affect of bacteriocin produced from Lactobacillus acidophilus(DSM20079) were on P.vulgaris, P.aeruginosa, K.pneumoniae, E.coli and A.baumannii( 30,24,23,19 and $17 \mathrm{~mm}$ ).Also, the affect of bacteriocin produced from Lactobacillus plantarum (DSM20174) on P.vulgaris, P.aeruginosa, K.pneumoniae, E.coli and A.baumannii were $(24,20,12,15$ and $15 \mathrm{~mm} \pm 1)$. On other hand, bacteriocin produced from Lactobacillus salivarius (DSM20555) have effect on P.vulgaris, P.aeruginosa, A.baumannii, K.pneumoniae and E.coli(24, 18, 16,15 and 12 $\mathrm{mm})$ (Table 6).

Also, bacteriocin have effect on MRSA in which bacteriocin of Lactobacillus salivarius (DSM20555) were the only one have effect on most cases isolated from blood stream $(20 \mathrm{~mm})$, but bacteriocin produced from Lactobacillus acidophilus(DSM20079) effect on other cases (23mm).

Table (6): Zones of inhibition of LAB against different multidrug resistant bacteria.

\begin{tabular}{|c|c|c|c|}
\hline \multirow{2}{*}{ Pathogenic bacteria } & \multicolumn{3}{|c|}{ Diameter zone of inhibition of bacteriocins(mm) } \\
\hline Isolated bacterial & $\begin{array}{l}\text { Lactobacillus acidophilus } \\
\text { bacteriocin (DSM20079) }\end{array}$ & $\begin{array}{c}\text { Lactobacillus planterum } \\
\text { bacteriocin (DSM20174 }\end{array}$ & $\begin{array}{c}\text { Lactobacillus salivarius } \\
\text { bacteriocin (DSM20555) }\end{array}$ \\
\hline E.coli & 19 & 15 & 12 \\
\hline K. pneumonia & 23 & 12 & 15 \\
\hline P. aeruginosa & 24 & 20 & 18 \\
\hline P. vulgaris & 30 & 24 & 16 \\
\hline A. baumannii & 17 & 15 & 11 \\
\hline Staph. aureus & 10 & 9 & 20 \\
\hline MRSA (blood sample) & 0 & 0 & 8 \\
\hline MRSA (urine sample) & 23 & 13 & 10 \\
\hline ESBL & 13 & 11 & 16 \\
\hline
\end{tabular}




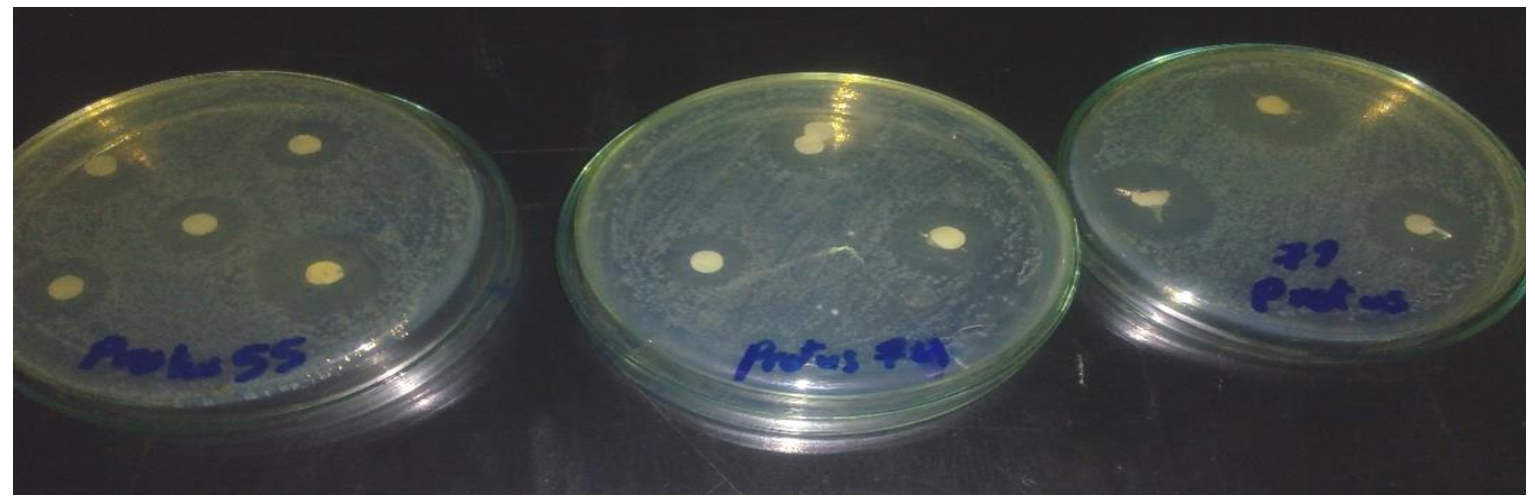

Figure (7): Effect of bacteriocin produced by Lactobacillus acidophilus (DSM20079), Lactobacillus planterum (DSM20174) and Lactobacillus Salivarus (DSM20555) on some pathogenic bacteria.

\section{Effect of Lactic acid bacteria on biofilm}

It was found that lactic acid bacteria also have an effect on the formation of biofilm, where they were grown on the biofilm of the pathogenic bacteria in the case of tube method and found that the blue color disappears (figure 7).

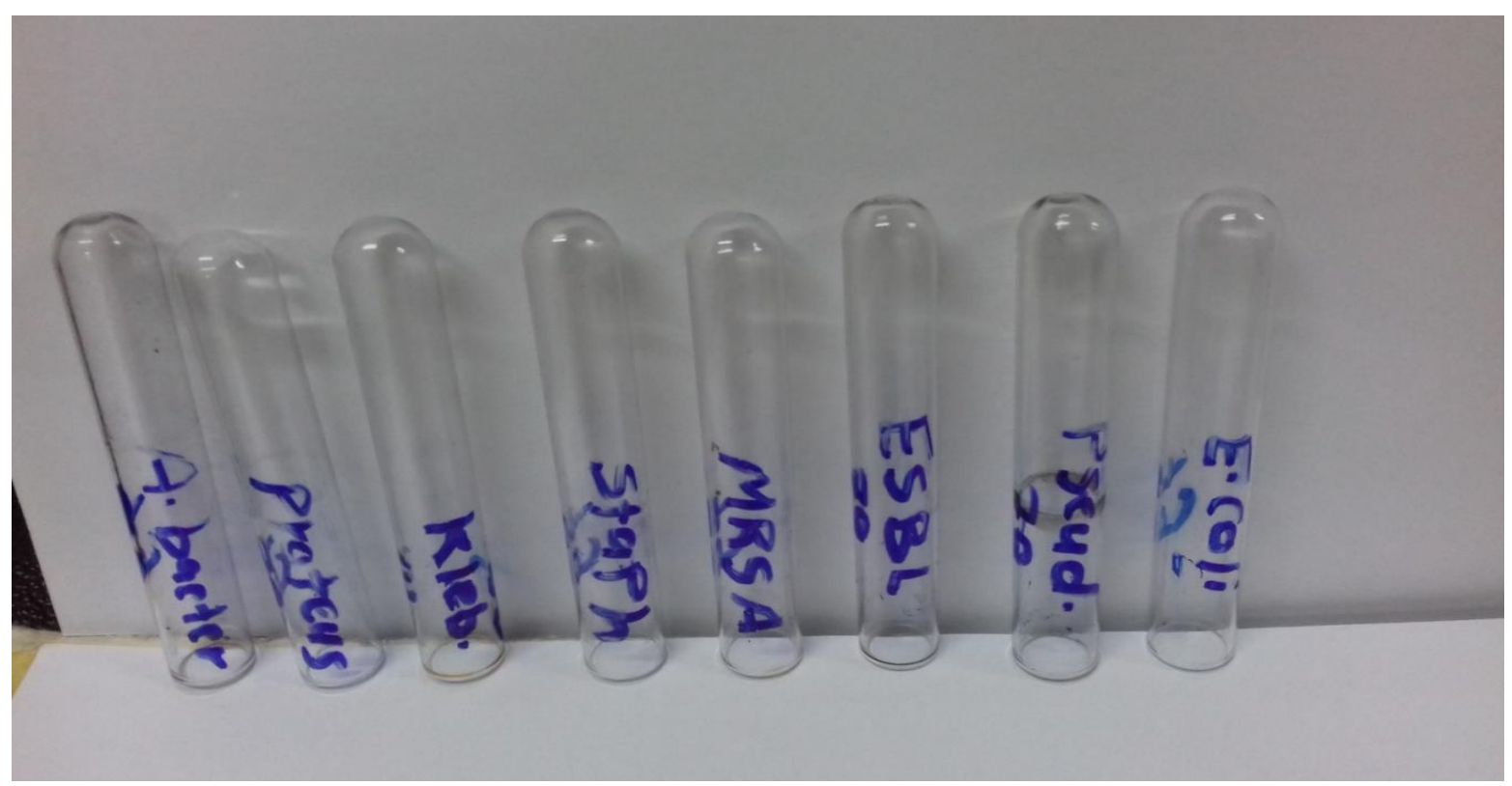

Figure (8): Effect of Lactobacillus acidophilus (DSM20079), Lactobacillus planterum (DSM20174) and Lactobacillus Salivarus (DSM20555) on biofilm of some pathogenic bacteria

\section{Discussion}

In the present study, a total of one hundred bacterial isolates were collected from many patients suffering from bacterial infection ( 55 females and 45 males) the results showed that (29.41\%) Escherichia coli, (23.53\%) Klebsiella Pneumoniae, (17.65\%) Staphylococcus aureus, (15.29\%) Pseudomonas 
aeruginosa, (8.24\%) Proteus vulgaris, (5.88\%) Acinetobacter baumannii. The bacterial isolates were obtained from 8 different specimens with the following percentage representations: urine (30.58 \%), blood (20\%), abscess (20\%), wound $(9.41 \%)$, throat and tube swab (5.88\%), ear discharges $(5.88 \%)$, vaginal swabs $(5.88 \%)$ and eye swab (2.35\%). Our results show that most isolates were recovered from urinary tract and E.coli was the most common agent isolated followed by K.pneumoniae. (Santigo et al., 2016) reported that E.coli was the most common agent isolated from UTI. Also, (CornejoJuárez et al., 2015) reported that (20\%) E. coli, (12\%) Staph.aureus, (12\%) Enterococcus faecium and (6\%) Acinetobacter baumannii (all were MDR). (Mulu et al., 2017) reported that E.coli followed by K.pneumoniae was isolated from urinary tract infection and P.aeruginosa was the most frequent isolate from ear infection. While, (Tabatabaei et al. 2015) reported that the most common site of infection was the respiratory tract (67.9\%) followed by the urinary tract (13.6\%). Among the pathogens isolated, Acinetobacter and Enterobacter were the most common (17.6\%) followed by E.coli (11\%). On other hand, (Hecini-Hannachi et al., 2016) were reported that most isolates were recovered from blood stream specimens $(47.05 \%)$. The study showed that Staph.aureus $(47.05 \%)$ was the most commonly isolated gram positive from blood stream followed to K.pneumoniae (41.17\%) that represent the most commonly of Enterobacteriaceae. These results is similar to the study, which was carried out on infection of bloodstream by (Latif $\boldsymbol{e t ~ a l . , ~ 2 0 0 9 ) . ~}$

The identification of bacteria in the clinical microbiology laboratory was performed by isolation the organism and studying it phenotypically by means of Gram staining, culture, and biochemical method, which were once the gold standard of bacterial identification (Wood et al., 2000). Recently, more precise and accurate identification requires DNA- based methods which are increasingly used. Moreover, this study used the PCR technique as an accurate tool for identification depending on specific type of genes. Antibiotic-resistant bacteria continue to be a major health concern worldwide. In this study, the $85 \%$ isolated pathogenic bacteria were examined against 17 different antibiotics. The results showed that Meropenem have a broad spectrum and high activity against all Gram negative and gram positive clinical bacterial isolates. The susceptibility rates of Meropenem were 76.9\%, 92\%, 85.7\%, 85\%, 80\% and $73.3 \%$ against P.aeruginosa, E.coli, Proteus vulgaris, Klebsiella pneumonia, Acinetobacter baumannii and Staph.aureus respectively. While, in this study, Cefadroxil and Piperacillin showed the lowest activity against all tested Gram- negative and Gram- positive bacterial isolates. The susceptibility patterns of Cefadroxil were $0 \%$ for all examined strains. The susceptibility patterns of Piperacillin were $28.57 \%, 23.07 \%$, 
$13.3 \%, 8 \%, 0 \%$ and $0 \%$ against Proteus vulgaris, Pseudomonas aeruginosa, Staph.aureus, E.coli, Klebsiella Pneumoniae and Acinetobacter baumannii.

Most isolates of Staph.aureus were susceptible to Vancomycin and Linezolid (80\% and 60\%) respectively (Bessa et al., 2013). The resistance to oxacillin is particularly important because it can give us the percentage of methicillinresistant Staphylococcusaureus (MRSA); in our study, a relevant percentage (40\%) of Staph. aureus was oxacillin resistant. While (Bessa et al., 2013) reported that the percentage of MRSA (21.8\%) of all Staph.aureus P.aeruginosa was resistant to erythromycin, amoxicillin/clavulanic acid and Cefotaxime. The resistance of P.aeruginosa to antibiotics was reported previously by other authors (Harvey et al., 2010). It was due to the ability of P.aeruginosa to form biofilm in patients. Also, E.coli, P.aeruginosa, K.pneumoniae and A.baumannii show high resistant rate to penicillin group (Amoxicillin/Clavulanic acid and Piperacillin) and cephalosporin group (Cefadroxil, Cefotaxime and Ceftazidime) and this similar to the observations of (Gelaw et al., 2013). Also, in this study most isolates of Gram negative bacteria have high resistance to macrolides class erythromycin and Azithromycin.

Biofilm producing bacteria are responsible for many nosocomial infections, inflammation and increasing the resistance of antibiotics. In our study, we detect biofilm of many isolates by two different methods (Tube and Congo red agar) and this was agreed with (Hassan et al., 2011). It was obtained that Acinetobacter baumannii; Klebsiella pneumoniae and Pseudomonas aeruginosa were the most isolates having biofilm and more resistance to selected antibiotics. But (Omar et al., 2017) showed that Staph.aureus and Pseudomonas aeruginosa were pathogens having biofilm that associated mainly to wound burns. (Nepal et al., 2017) showed that Klebsiella pneumoniae have the ability to adhere, multiply and persist on inanimate surface in the hospital environment causing nosocomial infections and it was ound that $(73.3 \%)$ Klebsiella Pneumoniae strains form biofilm.

Because of the increase of multidrug-resistant bacteria and the restriction on the use antibiotics due to its side effects there is need to some alternative techniques for treatment. Lactic acid bacteria have the ability to synthesize antimicrobial compounds (like bacteriocins) during their growth (Savadogo et al, 2004). The purpose of this study was to isolate bacteriocins from lactic acid bacteria for treatment/control multidrug-resistant bacteria.

Bacteriocins were isolated from cell free supernatant of LAB in MRS broth through precipitation method by adding 1N HCL. (Abd El.Fattah, 1999, Savadogo et al., 2004 and Abdelsamei et al., 2015) also preferred this technique on the basis of short time and bacteriocin quantity. Inhibitory activity of bacteriocins against antibiotics resistant bacteria were checked 
through agar diffusion disk method and zone of inhibition were measured. The diameters of inhibition zone against pathogenic bacteria were different. (Schved et al., 1993) described that the inhibition zone can determine the degree of sensitivity and resistance bacteria.

It was obtained from our results that the antimicrobial activity of L.acidophilus (DSM20079) recorded by the diameters of inhibition zone (mm) with mean values was $30,24,23,19,17$ and $10 \mathrm{~mm}$. against $P$. vulgaris, P. aeruginosa, K.pneumoniae, E. coli, A. baumannii and Staph.aureus respectively. Also, it has activity on Methicillin resistant Staph. aureus with inhibition zone $23 \mathrm{~mm}$ and ESBL with inhibition zone $13 \mathrm{~mm}$. Bacteriocin produced by L.salivarius (DSM20555) has inhibitory activity against pathogenic bacteria. It was obtained from our study that inhibition zone (mm) of L. salivarius (DSM2055) was 24, 18, 16, 15, 12 and $11 \mathrm{~mm}$. against $P$. vulgaris, $P$. pseudomonas, A.baumannii, K.pneumoniae, E.coli and Staph.aureus respectively. Also, L. plantarum (DSM20174) have antimicrobial activity against pathogenic bacteria with inhibition zone 24,20 , 15, 15, 12 and $9 \mathrm{~mm}$ against $P$. vulgaris, $P$. aeruginosa, A. baumannii, E-coli, $K$. pneumoniae and Staph.aureus respectively. From the previous results it was obtained that $L$. acidophilus have the highest activity against most isolated strains. Any researchers have highlighted the role of bacteriocins against pathogenic bacteria. (Zahid et al., 2015) were recorded that the antimicrobial activity of bacteriocins extracted from $L$. acidophilus have maximum against pathogenic bacteria such as Methicillin resistant Staphylococcus aureus, E.coli, Salmonella and Staphylococcus aureus by using well diffusion agar method. It was found that the average inhibition zone (mm) of L. acidophilus were 14.5, 12.5 and $10.0 \mathrm{~mm}$ against Bacillus subtilis, Staph.aureus and E.coli respectively. Also, (Sankaran, 2016) showed that cell free supernatant (bacteriocins) isolated from Lactic acid bacteria have antimicrobial activity against gram positive bacteria such as (Bacillus subtilis and Staphylococcus aureus) and gram negative bacteria such as (E.coli and K.pneumoniae). (Mahrous et al., 2013) also, found that bacteriocins isolated from $L$. acidophilus and $L$. plantarum have antimicrobial activity against food borne pathogenic as well as spoilage bacteria. It was found that the average diameter of inhibition zones measured ranged from 2$20 \mathrm{~mm}$ in size. More over in our study L. plantarum have high antimicrobial activity against tested pathogenic bacteria and these agreed with (Sikorska and Smoragiewicz, 2013) that observed that $L$. plantarum have inhibition activity against Staph.aureus and $P$. aeruginosa. 


\section{Conclusions}

The study revealed that most common isolates in clinical samples causing infection were $(29.41 \%)$ E.coli, (23.5\%) Klebsiella pneumoniae, (17.65\%) Staph.aureus, (15.29\%) Pseudomonas aeruginosa, (8.24\%) Proteus vulgaris and (5.88\%) Acinetobacter baumannii. Isolates showed high levels of resistance to amoxicillin/clavulanic acid, cefadroxil, erythromycin, cefotaxime. Majority of gram negative and gram positive isolates showed high susceptibility to meropenem. The rise of multidrug resistant strains problem may be solved by using alternative therapies such as lactic acid bacteria that would decrease our reliance on antibiotic use. The study also suggest that the production of bacteriocins from lactic acid bacteria such as L.acidophilus, $L$.plantarum and $L$.salivarus can be used as antimicrobial agent to decrease the infection caused by pathogenic bacteria. Therefore, LAB may be helpful in the treatment of antibiotic resistance.

\section{Reference}

Abd El-Fattah, A.B.S. (1999): Utilization of lactic acid baceria to overcome some microbial defects in dairy products. Ph.D. Thesis, Ain-Shams University.Egypt.

Abigail, L.T. (2010): Multidrug- Resistant Pseudomonas aeruginosa Infections. Thesis of M.Sc. Degree in Science of Nursing. Arizona University.

Abdelsamei, M. H.; Ibrahim, A. M. E.; El Sohaimy, A.S. and Saad A, M. (2015): Effect of storage on the activity of the bacteriocin extracted from Lactobacillus acidophilus. Benha Veterinary Medical Journal 28 (1) 216- 222. Abriouel, H., Benomar, N., Cobo, A., Caballero, N., Fuentes, M. A.F., Pérez-pulido, R., (2012): Characterization of lactic acid bacteria from naturally-fermented Manzanilla Alorena green table olives. Food Microbiol. 32:308-316.

Anastasiadou, S., Papagianni, M., Filiousis, G., Ambrosiadis, I., and Koidis, P. (2008): Pediocin SA-1, an antimicrobial peptide from pediococcus acidilacti NRRL B5627: Production conditions, Purification and characterization. Bioresource Technology, 99(13): 5384-5390.

Bauer, A.W.; Kirby, W.M.M.; Sherris, J.C. and Turck, M. (1966): Antibiotic susceptibility testing by standared single disk method. Am J Clin Pathol, 45(493-6).

Bessa, L.J.; Fazii, P.; Giolio, M.D. and Cellini, L. (2015): Bacterial isolates from infected wounds and their antibiotic susceptibility pattern: some remarks about wound infection. International Wound Journal ISSN, 17424801 . 
Cornejo- Juárez, P.; Vilar- Compte, D.; Pérez- Jiménez, C., NamendysSilva, S.A.; Sandoval- Hernnandez, S. and Volkow-Fernández, P (2015): The impact of hospital- acquired inections with multidrug- resistant bacteria in an oncology intensive care unit. International Journal of Infection Diseases, 4: $31-34$.

Cheensbourgh, M. (2006): District laboratory practice in tropical countries part II. $2^{\text {nd }}$ ed. NewYork: Cambridge University Press.

Chen, Y.C.; Lin, S.F.; Liu, C.J.; Jiang, D.D.; Yang, P.C. and Chang, S.C. (2001): Risk factors for ICU mortality in critically ill patients. J. Formos. Med.Assoc. 100(10):613-56.

Chumchalova, J.; Stiles, J.; Josephsen, J. and Plockova, M. (2004): Characterization and purification of acidocin $\mathrm{CH} 5$ a bacteriocin produced by Lactobacillus acidophilusCH5. Journal of Applied Microbiology 96: 10821089.

CLSI (2006): Performance standards for antimicrobial susceptibility testing; Seventeenth Information Supplement. CLSI document M100- S17, Clinical and Laboratory Standards Institute Wayne Pennsylvania.

Delle Rose, D.; Sordillo, P.; Gini, S.; Meledandri, M.; Gallo, M.T.; Prignano, G.; Caccese, R.; D'Ambrosio M. (2015): Microbiologic characteristics and predictors of mortality in bloodstream infections in intensive care unit patients: A 1-year, large, prospective surveillance study in 5 Italian hospitals. Am. J. Infect. Control. 43(11):1178-1183.

De vuyst, L. (1995): Nutritional factors affecting nisin production by Lactococcus Lactis subsp. Lactis NIZO 22186 in a synthetic medium. J. Appl. Bacterial. 78: 28- 33.

Forbes, B.A.; Sahm, D.F. and Weissfeld, A.S. (1998): Bailley and Scott Diagnostic Microbiology. 10th ed., Mosby.

Gelaw, A.; Gebre Selassie, S.; Tiruneh, M. and Fentie, M. (2013): Antimicrobial susceptibility patterns of bacterial isolates from patients with postoperative surgical site infection, health professionals and environmental samples at a tertiary level hospital, North West Ethiopia. International Journal of Pharmaceutical Sciences Review and Research, 3(1): 1-9.

Gómez, N. C., Abrioul, H., Grande, M. J., Pulido, R. P., and Gálvez, A. (2012): Effect of enterocin AS-48 in combination with biocides on planktonic and sessile Listeria monocytogenes. Food Microbiol.30:51-58.

Harvey, R.; Funk, J.; Wittum, T.E. and Hoet, A.E. (2010): A metagenomic approach for determining prevalence of tetracycline resistance genes in the fecal flora of conventionally raised feedlot steers and feedlot steers raised without antimicrobials. Am. J. Vet. Res., 70: 198-202. 
Hassan, A.; Usman, J.; Kaleem, F.; Omair, M.; Khalid, A. and Iqbal, M. (2011): Evaluation of different detection methods of biofilm formation in the clinical isolates. Braz Journal Infect Disease, 15 (4): 305-311.

Hecini- Hannachi, A.; Bentchouala, C.; Lezzar, A.; Laouar, H.; Benlaabed, K. and Smati, F. (2016): Multidrug- resistant bacteria isolated from patients hospitalized in Intensive Care Unit in University Hospital of Constantine, Algeria. African Journal of Microbiology Research, 10(33): 1328-1336.

Hurst, A. (1966): Biosynthesis of the antibiotic Nisin by whole Streptococcus lactis organisms. Genetic Microbiological Journal, 44: 209-220.

Jack, R. W.; Tagg, J. R. and Ray, B. (1995): Bacteriocins of Gram- positive bacteria. Microbiol. Rev., 59: 171- 200.

Kanmani, P., Satish Kumar, R., Yuvaraj, N., Paari, K. A., Pattukumar, V., and Arul, V. (2013): Probiotics and its functionally valuable products $-A$ review Crit. Rev. Food Sci. 53: 641-658.

Latif, S.; Anwar, M.S. and Ahmad, I. (2009): Bacterial pathogens responsible for blood stream infection (BSI) and pattern of drug resistance in a tertiary care hospital of Lahore. Biomedica, 25: 101-105.

Levy, S.B. (1997): Antibiotic resistance: An ecological imbalance. In Antibiotic Resistance: Origins, Evolution,Selection and Spread edited by DJ Chadwick, J Goode. Wiley,Chichester (Ciba Foundation Symposium 207) West Sussex,England. pp. 1-14. (ISBN 047197105 7).

Mahrous, H.; Mohamed, A.; Abd El-Mongy, M.; El-Batal, A.I. and Hamza, H.A. (2013): Study bacteriocin production and optimization using new isolates of Lactobacillus spp. isolated from some dairy products under different culture conditions. Food and Nutrition Sciences, 4: 342-356.

Martin, S.J. and Yost, R.J. (2011): Infectious diseases in the critically ill Patients. J. Pharm. Pract. 24:35-43.

Mc Dermott, P.F.; Tyson, G.H.; Kabera, C.; Chen, Y., Li, C., Folster, J.P., Ayers, S.L., Lam, C., Tate, H.P. and Zhao, S. (2016): Whole-genome, sequencing for detecting antimicrobial resistance in nontyphoidal Salmonella. Antimicrobe. Agents Chemother, 60: 5515-5520.

Muller, H.J. and Hinton, J. (1941): A protein-free medium for primary isolation of the Gonococcus and Meningococcus. Proc.Soc. Exp. Biol. and Med. 48: 330-333.

Mulu, W.; Abera, B.; Yimer, M.; Hailu, T.; Ayele, H. and Abate, D. (2017): Bacterial agents and antibiotic resistance profiles of infections from different sites that occurred among patients at Debre Markos Referral Hospital, Ethiopia: a cross- sectional study.BMC Research Notes, 10: 254.

Nepal, H. P.; Neopane, P.; Shrestha, R.; Gautam, R.; Paudel, R.; Ansari, S.; Shrestha, S. and Thapa, S. (2017): Biofilm formation and antimicrobial 
resistance in Klebsiella pneumoniae isolated from patients visiting a tertiary care center of Npal. Asian Pacific Journal of Tropical Disease, 7(6): 47-351.

Omar, A.; Wright, J. B.; Schultz, G.; Burrell, R. and Nadworny, P. (2017): Microbial biofilm and chronic wounds. Journal of Microorganisms, 5(9):15.

O' Neill, J., (2016): Tackling drug-resistant infections globally:Final report and recommendations.Rev.Antimicrobe.Resist.(May(19)).

http://amrreview.org/publications.html.

Raja, N.S. and Singh, N.N. (2007): Antimicrobial susceptibility pattern of clinical isolates of Pseudomonas aeruginosa in tertiary care hospital. J Microbiol Immunol Infect. 40 (1): 45-49.

Saavedra, L.; Minahk, C.; Holgado, A. P.; De R. and Sesma, F. (2004): Enhancement of the enterocin CRL 35 activity by a synthetic peptide derived from the $\mathrm{NH}_{2-}$ terminal sequence. Antimicrob. Agents Chemother, 48 (7)2778- 2781.

Salyers, A.A. (1995): Antibiotics resistance transfers in the mammalian intestinal tract. Implications for human health, Food safety and biotechnology Springer verlag, Heidelberg.

Sankaran, k.M.(2016): Isolation of Lactic Acid Bacteria (Lab) Producing Bacteriocin from Piyush and Aagal (Known Concentrate).Journal of Food and Dairy Technology, P- ISSN, 2347- 235.

Santiago, R.; Oscar, E.P.; Andres, F.A.; Jorge, S.; Lina, M.T. and Fabian, J. (2016): Urinary tract infection leading to hospital admission during the first year after kidney transplantation: A retrospective cohort study. Transplantation Reports, 1: 18-22.

Savadogo, A.; Ouattara, C.A.T. and Traore, A.S. (2004): Antimicrobial activity of lactic acid bacteria strains isolated from Burkina Faso fermented milk. Pakistan Journal of Nutrition, 3 (3): 174-179.

Schved, F.; Lalazar, A.; Henis, Y, and Junen, J. (1993): Purification partial characterization and plasmid-linkage pediocin SJ-1, a bacteriocin produced by Pediococcus acidilactici. J. Appl. Bacteriol., 74: 67- 77.

Sikorska, H. and Smoragiewicz, W. (2013): Role of Probiotic in the Prevention and Treatment of Methicillin-Resistant Staphylococcus aureus Infec. International Journal of Antimicrobial Agents, 42: 475-481.

Simova, E. D.; Beshkova, D. B.; Dimitorv, Zh. P. (2009): Characterization and antimicrobial spectra of bacteriocins produced by lactic acid bacteria isolated from traditional Bulgarian dairy products. Journal of Applied Microbiology, 106: 692- 701.

Stiles, M, E. (1996): Biopreservation by lactic acid bacteria, Antonie van Leuwenhoek, 70: 331-345. 
Tabatabaei, S. M.; Pour, F.B and Osmani, S. (2015): Epidemiology of hospital- acquired infections and related anti- microbial resistance patterns in a Tertiary- care teaching hospital in Zahedan, South east and Iran. Int. J. Infect., 2 (4): e29079.

Tagg, J.R.; Dajani, A.S. and Wannamaker, L.W. (1976): Bacteriocins of gram positive bacteria. J. Clin. Microbiol., 40:722-756.

Todorov, S. D. and Dicks, L. M. T. (2005): Lactobacillus plantarum isolated from molasses produces bacteriocins active against gram- negative bacteria. Enzyme Microbial. Technol., 36: 318-326.

Wood, P. C. Y.; Leung, K. W. and Yuen, K. Y. (2000): Identification by $16 \mathrm{~S}$ ribosomal RNA gene sequencing of an Enterobacteriaceae species from a bone marrowransplant recipient. Journal of Clinical Pathology. Molecular Pathology, 53: 211- 215.

Viedma, P. M., Ercolini, D., Ferrocino, I., Abriouel, H., Omar, N. B., López., R. L., (2010): Effect of polythene film activated with enterocin EJ97 in combination with EDTA against Bacillus coagulans. LWT-Food Sci, Technol. 43:541-518.

Zahid, M., Ashraf, M., Arshad, M., Muhammad, G., Yasmin, A. and Muhammad, H.A.H. (2015): Antimicrobial activity of bacteriocins isolated from lactic acid bacteria against resistant pathogenic strains. International Journal of Nutrition and Food Science, 4(3): 32.

Zawack, K., Li, M., Booth, J.G., Love, W., Lanzas, C.and Grohn, Y.T. (2016): Monitoring antimicrobial resistance in the food study chain and its implications for FAD policy initiatives. Antimicrob. Chemother, 60: 53025311. 
استخدام بكتيريا حمض البروبيوتيك للسيطرة على البكتيريا المقاومة للمضادات الحيوية المتعددة المعزولة من العدوى السريرية

جمال أبو سبع لاشين 1 , ايمان التهامى2, أحمد عسكورة2, فاطمة الزهراء محمود2 1 قسم النبات_كلية العلوم- جامعة الزقازيقــ الزقازيق.

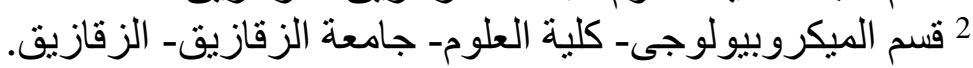

الملخص العربى

اتجهت الأبحاث الان لاستخدام بكتريا البروبيوتلك كبديل امن للمضادات الحيوية بسبب زيادة البكتريا المقاومة لها ولان البروبيوتلك تعتبر بكتريا نافعة وتثبط نمو الكائنات الضارة بافرازها للمركبات الحيوية النشطة مثل البكتريوسين وفى هذه الدراسة تم أخذ 100 عينة من مرضى مختلفين فى الاعمار و الجنس انثى( 55 و 45 ذكر) و الذين يعانون من العدوى البكترية :26عينة بول و24 عينة دم و22 عينة من خر اج و8 عينة من جروح و 5 مسحات من الاذن و 5 مسحات من المهبل و6 مسحات من الحلق و4 مسحات من العين ومن خلال الزرع وجد أن منهم 85 عينة مسببة للعدوى والمرض وقد تم استخدام طرق بيولوجية وبيوكيميائية لتعريف وتحديد أنواع البكترية الممرضة وقد تم التأكيد على هذه الطرق باستخدام PCR. وقد أظهرت هذه الدر اسة أن أكثر العزلات شيو عا كانت بكتريا ايشيريشيا كولاى بنسبة (29.41\%) يليها بكتريا كليبسيلا نيمويى بنسبة (23.53\%) يليها الاستافيلوكوكاس اورياس بنسبة (15.29\%) يليها بكتريا سودوموناس أوريجينوزا بنسبة (17.65\%) يليها بكتريا بروتياس فولجاريس بنسبة (8.24\%) وبكتريا الأسينتوباكتر باومنى بنسبة (5.88\%). كما أظهرت أنه من بين 17 مضاد حيوى وجد ان الميرونام هو أكثر المضادات الحيوية تأثثرا على كل من البكتريا السالبه الجرام والموجبة الجر ام. كما أنه تم تحديد البيوفيلم بطريقتين مختلفتين أتضح أن معظم العز لات كانت مقاومة للمضادات الحيوية.

تم عزل البكتريوسين من ثلاثة أنواع من بكتريا حمض اللاكتيك وهما لاكتوباسيللس اسيدوفيللس و لاكتوباسيللس بلانتار ام و لاكتوباسيللس سيلفارس حيث كانو الهم تأثثر على كل من البكتريا السالبة الجرام والموجبة الجرام حيث أظهرت لاكتوباسيلس اسيدوفيللس كان أكثرهم تأثثرا على العزلات الممرضة ، كما بينت الدر اسة أن اللاكتوباسيللس سيلفارس لها تأثثر كبير على المرسا. 